\title{
Renoprotective effects of an angiotensin II receptor blocker in experimental model rats with hypertension and metabolic disorders
}

\author{
Daisuke Watanabe $^{1}$, Akiyo Tanabe ${ }^{1}$, Mitsuhide Naruse ${ }^{2}$, Shunichi Morikawa ${ }^{3}$, Taichi Ezaki ${ }^{3}$ and Kazue Takano ${ }^{1}$
}

Metabolic syndrome (MS) is an independent risk factor for chronic kidney diseases. As the renin-angiotensin system (RAS) is known to have a key role in renal damage, blockade of RAS may show renoprotective effects in MS. In this study, we investigated the renoprotective effects and mechanisms of action of an angiotensin receptor blocker (ARB) in spontaneously hypertensive (SHR/NDmcr-cp) rats as a model of MS. Male SHR/NDmcr-cp rats at 9 weeks of age were divided into three groups, each of which was treated for 12 weeks with vehicle, hydralazine $\left(7.5 \mathrm{mg} \mathrm{kg}^{-1}\right.$ per day, p.o.) or ARB (olmesartan, $5 \mathrm{mg} \mathrm{kg}^{-1}$ per day, p.o.). Blood pressure and urinary protein (UP) excretion were monitored. Kidney tissues were subjected to histological, immunohistochemical and molecular analyses. UP excretion increased with age in vehicle-treated SHR/NDmcr-cp rats compared with that in age-matched WKY/Izm rats. In addition, there was significant glomerular damage (increased glomerular sclerosis index, desmin staining and proliferating cell nuclear antigen (PCNA)-positive cells, electron microscopic findings of podocyte injury) and tubulointerstitial damage (increased tubulointerstitial fibrosis index, type IV collagen staining, PCNA-positive cells and expression of TGF- $\beta$ mRNA) in vehicle-treated SHR/NDmcr-cp rats compared with that in control rats. All the findings that related to glomerular and tubulointerstitial damage were significantly improved by ARB. Hydralazine mitigated the observed renal damage but was much less effective than ARB, despite similar decreases in blood pressure. There were no significant differences in glucose and lipid metabolism among vehicle-treated, hydralazine-treated and ARB-treated SHR/NDmcr-cp animals. These data suggest that RAS is deeply involved in the pathogenesis of renal damage in MS, and ARBs could provide a powerful renoprotective regimen for patients with MS.

Hypertension Research (2009) 32, 807-815; doi:10.1038/hr.2009.106; published online 7 August 2009

Keywords: metabolic syndrome; angiotensin II; glomerular damage; angiotensin type 1 receptor antagonist; podocyte

\section{INTRODUCTION}

Metabolic syndrome (MS) is a pathological condition characterized by a combination of visceral obesity, hypertension, glucose intolerance and dyslipidemia. Any of these disorders individually, as well as an accumulation of these hemodynamic and metabolic disorders, could be an independent risk factor for cardiovascular and chronic kidney diseases. ${ }^{1}$ In addition to hypertension and diabetes mellitus, recent evidence suggests that obesity is correlated with renal injury. ${ }^{2,3}$ Proteinuria has been observed in obese patients, including those without a history of hypertension and/or diabetes mellitus. ${ }^{4,5}$ Furthermore, body weight reduction ameliorates proteinuria in obese patients with chronic proteinuric nephropathies. ${ }^{6}$ Glomerular hyperfiltration ${ }^{7,8}$ is a proposed etiology for obesity-related glomerulopathy. ${ }^{9}$ In addition, microalbuminuria and proteinuria resulting from renal damage further injure the kidney, resulting in a cycle that perpetuates renal dysfunction. ${ }^{10,11}$
The renin-angiotensin system (RAS) is known to be deeply involved in progression of renal injury. ${ }^{12}$ RAS blockade has a renoprotective effect, which was shown in clinical trials for patients with diabetic nephropathy. ${ }^{13,14}$ In patients with MS associated with obesity, hyperinsulinemia, activation of the sympathetic nervous system ${ }^{15}$ and excessive production of angiotensinogen by visceral adipose tissue, ${ }^{16}$ these conditions lead to an inappropriate activation of RAS and consequently to renal injury. ${ }^{17}$ Therefore, RAS is a potential molecular target of treatment for renal injury in MS. Mechanistic details about the renoprotective effects of RAS blockade are still unclear.

Spontaneously hypertensive (SHR/NDmcr-cp) rats with a genetic mutation in the leptin receptor gene ${ }^{18}$ exhibit a variety of metabolic abnormalities, including hypertension, obesity, glucose intolerance, hyperinsulinemia and dyslipidemia. Therefore, these rats are widely accepted as an experimental model for studies on MS. Otsuka Long Evans Tokushima Fatty (OLETF) rats and Goto-kakizaki (GK) rats

${ }^{1}$ Department of Medicine, Institute of Clinical Endocrinology, Tokyo Women's Medical University, Tokyo, Japan; ${ }^{2}$ Division of Endocrinology, Metabolism and Hypertension, Kyoto Medical Center, Clinical Research Institute, National Hospital Organization, Kyoto, Japan and ${ }^{3}$ Department of Anatomy and Developmental Biology, Tokyo Women's Medical University, Tokyo, Japan

Correspondence: Dr A Tanabe, Department of Medicine, Institute of Clinical Endocrinology, Tokyo Women's Medical University, 8-1, Kawadacho, Shinjuku-ku, Tokyo 162-8666, Japan. 
have been used as a model for type II diabetes mellitus, whereas SHR/ NDmcr-cp rats are associated with a more prominent accumulation of visceral fat and are therefore considered to be a better model for advanced MS. In this study, we investigated the renoprotective effects of an angiotensin II (Ang II) receptor blocker (ARB) on functional and morphological changes in kidneys of SHR/NDmcr-cp rats.

\section{METHODS}

\section{Experimental animals and protocols}

Male SHR/NDmcr-cp rats and Wistar-Kyoto rats (WKY/Izm) were obtained from Japan SLC (Shizuoka, Japan). SHR/NDmcr-cp rats (9-week old) were randomly divided into three groups and treated for 12 weeks as follows: (1) vehicle-treated SHR/NDmcr-cp group (vehicle, $n=10$ ), (2) hydralazine group (7.5 mg kg ${ }^{-1}$ per day, p.o., $n=10$ ) and (3) ARB group (olmesartan, $5 \mathrm{mg} \mathrm{kg}^{-1}$ per day, p.o., $n=10$; Daiichi-Sankyo, Tokyo, Japan). WKY/Izm rats (9-week old, $n=10)$ were treated with vehicle for 12 weeks as a normal control. In addition, SHR/NDmcr-cp rats $(n=5)$ and WKY/Izm rats $(n=5)$ were studied to compare their baseline characteristics at 9 weeks of age. Body weight and systolic blood pressure (SBP) were measured by the tail-cuff method (Softron BP-98A; Softron, Tokyo, Japan) every 3 weeks. The study was performed in accordance with the Guidelines for the Care and Use of Animals of the Tokyo Women's Medical University and approved by the institutional committee for animal experiments.

\section{Blood and urine biochemistry}

Twenty-four-hour urine samples were collected by placing animals in metabolic cages before and after 12 weeks of treatment. After the treatment period, blood samples were collected from six rats from each group under pentobarbital anesthesia $\left(40 \mathrm{mg} \mathrm{kg}^{-1}\right.$, i.p.). We determined serum creatinine, total cholesterol, triglyceride and glycosylated hemoglobin (HbAlc) levels using an autoanalyzer (Mitsubishi Chemical Medience, Tokyo, Japan). Creatinine clearance (24-h Ccr) was calculated as described previously.19

\section{Histological and immunohistochemical analyses}

SHR/NDmcr-cp rats and WKY/Izm rats at 9 weeks of age $(n=5)$ and after 12 weeks of treatment $(n=4)$ were anesthetized with pentobarbital. Fluorescein isothiocyanate-labeled Lycopersicon esculentum lectin (tomato lectin: Vector Laboratories, Burlingame, CA, USA) was injected into the tail vein and allowed to circulate for $3 \mathrm{~min}$ before the rats were perfused with a fixative to enable the visualization of blood vessels. The chest was opened rapidly and the vasculature was perfused for $3 \mathrm{~min}$ at a pressure of $120 \mathrm{~mm} \mathrm{Hg}$ with $4 \%$ paraformaldehyde in $0.1 \mathrm{M}$ phosphate-buffered saline (PBS, $\mathrm{pH}$ 7.4) through a cannula inserted into the aorta from the left ventricle. Kidneys were removed, cut longitudinally and fixed in the same solution at $4{ }^{\circ} \mathrm{C}$ for $2 \mathrm{~h}$. After the kidneys were embedded in paraffin, $4-\mu \mathrm{m}$-thick sections were cut and stained with periodic acid-schiff and Azan solution for the evaluation of glomerular sclerosis ${ }^{20}$ and tubulointerstitial fibrosis, ${ }^{21}$ respectively.

Glomerular sclerosis was semiquantitatively evaluated using kidney sections stained with periodic acid-schiff as described previously. ${ }^{20}$ Briefly, 20 glomeruli per rat ( $n=4$ per group) were assessed on periodic acid-schiff-stained sections and levels of glomerular sclerosis in each glomerulus were scored as follows: 0 , no sclerosis; $1+, 1-25 \%$; $2+, 25-50 \% ; 3+, 50-75 \%$ and $4+, 75-100 \%$. To evaluate tubulointerstitial fibrosis, we assessed 20 fields per rat ( $n=4$ per group) on Azan-stained sections $(\times 200)$. Semiquantitative analysis in each field was assessed as follows: 0 , absent; 1 , mild; 2 , moderate; 3 , severe and 4 , very severe. ${ }^{20}$

After fixation, renal tissues were rinsed several times with PBS, and further immersed in PBS containing a graded series (up to 30\%) of sucrose concentrations at $4{ }^{\circ} \mathrm{C}$ overnight. Thereafter, the tissues were embedded in Tissue-Tek OCT compound (Sakura Finetek, Torrance, CA, USA) and snap-frozen in liquid nitrogen. Cryostat sections $(10-\mu \mathrm{m}$ thick) were incubated with a polyclonal anti-rabbit desmin antiserum (1:100; Abcam, Cambridge, UK) or a polyclonal anti-rabbit type IV collagen antiserum (1:400; LSL, Tokyo, Japan). After several washes with PBS, the sections were incubated for $45 \mathrm{~min}$ with a secondary antibody labeled with Cy3 for desmin and type IV collagen staining (Jackson Immuno Research, West Grove, PA, USA). The sections were mounted in Vectashield (Vector Laboratories) and analyzed by a Leica TCSSL confocal laser-scanning microscope (Leica, Wetzler, Germany). Proliferating cell nuclear antigen (PCNA)-positive cells were identified with a polyclonal rabbit anti-PCNA (1:100; Bethyl Laboratories, Montgomery, TX, USA), followed by incubation with a biotinylated anti-rabbit $\operatorname{IgG}(1: 200)$ as a secondary antibody. Immunopositive sites were detected with HRP-conjugated streptavidin and visualized by incubating with $3^{\prime}$-diaminobenzidine hydrochloride solution (Dojin Chemicals, Kumamoto, Japan).

A total of 20 glomeruli and 20 fields per rat ( $n=4$ per group) were randomly analyzed for quantification of desmin and PCNA-positive cells in glomerular regions and for type IV collagen and PCNA-positive cells in interstitial regions. The intensity of immunostaining was recorded in a semiquantitative manner as follows: 1, faint; 2, weak; 3 , moderate and 4 , intense. The average of all parameters was calculated for each group to facilitate comparisons between groups. Histological assessment was performed by a pathologist blinded to the treatment group.

\section{Transmission electron microscopic analyses}

After perfusion with $4 \%$ paraformaldehyde in PBS, the kidney was cut into small blocks and further immersed in $2.5 \%$ glutaraldehyde plus $4 \%$ paraformaldehyde in $0.1 \mathrm{moll}^{-1}$ phosphate buffer ( $\mathrm{pH} 7.4$ ) for $2 \mathrm{~h}$. The specimens were postfixed with $2 \%$ buffered osmium tetroxide for $2 \mathrm{~h}$ and embedded in Epon epoxy resin after dehydration through a graded series of ethanol. The specimens were cut with an ultramicrotome. Ultrathin sections were double stained with uranyl acetate and lead citrate and examined with an Hitachi H-7000 electron microscope (Hitachi, Tokyo, Japan).

\section{Expression of TGF- $\beta$ mRNA}

Kidneys obtained at the termination of the experiment were rapidly frozen and stored at $-80^{\circ} \mathrm{C}$ for mRNA analyses. Expression of TGF- $\beta$ mRNA was quantified by real-time quantitative reverse transcription PCR using the ABI PRISM 7700 Sequence Detection System (Applied Biosystems, Tokyo, Japan). Expression levels of TGF- $\beta$ mRNA were compared semiquantitatively by correcting for the expression of glyceraldehyde-3-phosphate dehydrogenase mRNA.

\section{Statistical analyses}

All values were expressed as mean \pm s.e. One-way analysis of variance with post-hoc multiple comparisons and Sheffe's test were used for comparison between three groups. Mann-Whitney's $U$-test was used for comparison between two groups. Statistical analysis was performed with StatView software (Abacus Concepts, Berkeley, CA, USA). A value of $P<0.05$ was considered as statistically significant.

\section{RESULTS}

\section{Body weight, SBP and kidney weight}

The body weight of all rats in all the SHR/NDmcr-cp groups significantly increased with age and was approximately $170 \%$ higher than that of WKY/Izm rats at 21 weeks. There was no significant difference in body weight between the three SHR/NDmcr-cp groups (Figure 1a). SBP was significantly elevated with age in the vehicletreated SHR/NDmcr-cp group than in WKY/Izm rats. There was a significant but similar extent of decrease in SBP in both the hydralazine- and ARB-treated groups after 12 weeks of treatment (Figure 1b). Kidney weight to body weight ratio was significantly higher in the SHR/NDmcr-cp groups than in WKY/Izm rats at 21 weeks of age (2).

\section{Blood and urine biochemistry}

At 9 weeks of age, there were no significant differences in 24-h Ccr, serum creatinine concentration, serum triglycerides concentration, and HbAlc between the vehicle-treated SHR/NDmcr-cp group and WKY/Izm rats. Serum total cholesterol was slightly but significantly higher in the SHR/NDmcr-cp group than in the WKY/Izm group (Table 1). In addition, urinary protein (UP) excretion in the 

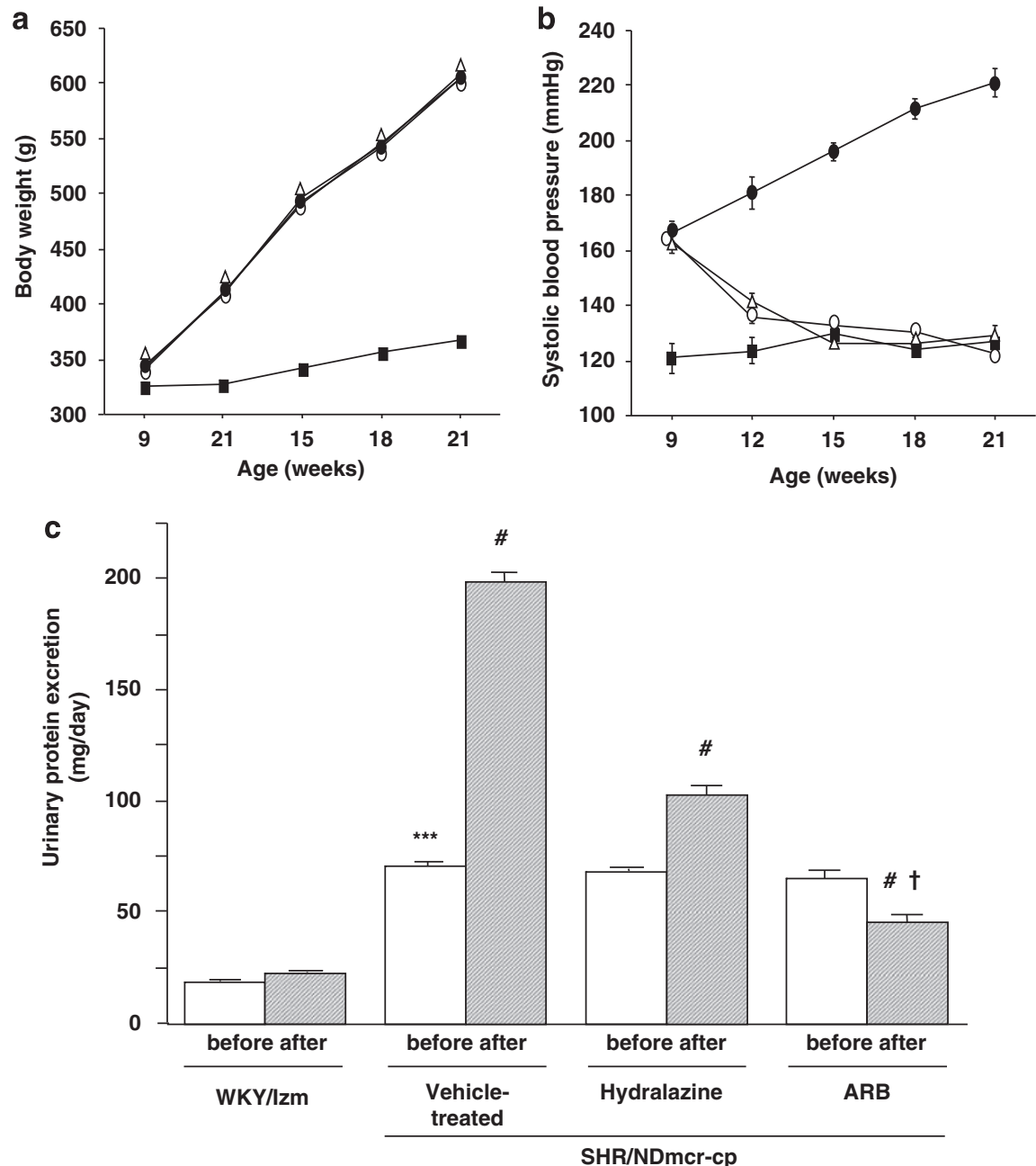

Figure 1 Effect of antihypertensive drugs on body weight, systolic blood pressure and urinary protein excretion/age-related change of body weight (a) and systolic blood pressure (b) in the WKY/Izm group ( $\square$ ), the vehicle-treated SHR/NDmcr-cp group $(\bullet)$ the hydralazine group ( $\square$ ) and in the angiotensin II receptor blocker (ARB) group (O). Urinary protein excretion (c) in the WKY/Izm group, the vehicle-treated SHR/NDmcr-cp group, the hydralazine group and in the ARB group before and after 12 weeks of treatment. ${ }^{*} P<0.05$ vs. WKY/lzm group before treatment, ${ }^{\#} P<0.05$ vs. corresponding SHR/NDmcr-cp group before treatment, ${ }^{\dagger} P<0.05$ vs. vehicle-treated SHR/NDmcr-cp group or the hydralazine group after treatment.

Table 1 Baseline characteristics of WKY/lzm rats and SHR/NDmcr-cp rats at the age of 9 weeks

\begin{tabular}{|c|c|c|}
\hline & $W K Y / I z m$ & $\begin{array}{c}\text { SHR/ } \\
\text { NDmcr-cp }\end{array}$ \\
\hline$n$ & 5 & 5 \\
\hline Urinary protein excretion (mg day ${ }^{-1}$ ) & $25.9 \pm 1.5$ & $73.1 \pm 2.7$ \\
\hline 24-h Ccr (ml min-1) & $3.57 \pm 0.09$ & $3.41 \pm 0.13$ \\
\hline 24-h Ccr (ml min-1) per $100 \mathrm{~g}$ body weight & $1.10 \pm 0.02$ & $0.97 \pm 0.04$ \\
\hline Serum creatinine concentration (mg per 100 ml) & $0.21 \pm 0.01$ & $0.20 \pm 0.01$ \\
\hline Serum total cholesterol concentration (mg per $100 \mathrm{ml}$ ) & $53.4 \pm 1.1$ & $65.6 \pm 2.3^{a}$ \\
\hline Serum triglycerides concentration (mg per $100 \mathrm{ml}$ ) & $108.8 \pm 4.0$ & $113.2 \pm 2.9$ \\
\hline $\mathrm{HbA}_{1 \mathrm{C}}(\%)$ & $3.22 \pm 0.10$ & $3.32 \pm 0.10$ \\
\hline
\end{tabular}

Abbreviations: $\mathrm{Ccr}$, creatinine clearance; $\mathrm{HbA}_{1 \mathrm{c}}$, hemoglobin $\mathrm{A}_{1 \mathrm{c}}$.

Data are expressed as the mean \pm s.e.

a $P<0.05$ vs. WKY/Izm.

SHR/NDmcr-cp group was threefold higher than that in WKY/Izm rats at the age of 9 weeks (Table 1), and the observed proteinuria increased with age (Figure 1). There was a significant decrease in UP excretion in both hydralazine- and ARB-treated groups after 12 weeks of treatment, but the decrement was more remarkable in the latter than in the former group (Figure 1c).

There were no significant differences in serum creatinine levels between WKY/Izm rats and all of the SHR/NDmcr-cp groups. The 24-h Ccr was decreased in the vehicle-treated SHR/NDmcr-cp group than in WKY/Izm rats. It was significantly improved in the ARBtreated group, but the rats treated with hydralazine did not exhibit the same improvement. Although serum total cholesterol, triglyceride and HbAlc levels were significantly elevated in all the SHR/NDmcr-cp groups over the WKY/Izm rats after 12 weeks of treatment, no significant difference was observed between the three SHR/NDmcrcp groups (Table 2).

\section{Histological and immunohistochemical findings}

The kidneys seemed histologically normal in both SHR/NDmcr-cp rats and WKY/Izm rats at 9 weeks of age, and no significant differences were observed between the two groups (Figures 2a-d). Although no characteristic features of focal segmental glomerulosclerosis were observed in the vehicle-treated SHR/NDmcr-cp group, 
Table 2 Renal function, biochemical characteristics and kidney weight of WKY/Izm rats and SHR/NDmcr-cp rats after 12 weeks of treatments

\begin{tabular}{|c|c|c|c|c|}
\hline & \multirow[b]{2}{*}{ WKY/Izm } & \multicolumn{3}{|c|}{$S H R / N D m c r-c p$} \\
\hline & & Vehicle-treated & Hydralazine & $A R B$ \\
\hline $24-\mathrm{hCcr}\left(\mathrm{ml} \mathrm{min}^{-1}\right)$ & $3.30 \pm 1.80$ & $1.57 \pm 0.17^{\mathrm{a}}$ & $1.91 \pm 0.05^{\mathrm{a}}$ & $2.78 \pm 0.08^{\mathrm{a}, \mathrm{b}, \mathrm{c}}$ \\
\hline 24-hCcr (ml min ${ }^{-1}$ ) per $100 \mathrm{~g}$ body weight & $0.90 \pm 0.03$ & $0.25 \pm 0.03$ & $0.31 \pm 0.01$ & $0.47 \pm 0.01$ \\
\hline Serum creatinine concentration (mg per $100 \mathrm{ml}$ ) & $0.29 \pm 0.02$ & $0.29 \pm 0.03$ & $0.25 \pm 0.03$ & $0.27 \pm 0.02$ \\
\hline $\mathrm{HbA}_{1 \mathrm{C}}(\%)$ & $3.96 \pm 0.10$ & $7.50 \pm 0.1^{\mathrm{a}}$ & $7.54 \pm 0.11^{\mathrm{a}}$ & $7.52 \pm 0.11^{\mathrm{a}}$ \\
\hline Kidney weight (g) per $100 \mathrm{~g}$ body weight & $0.55 \pm 0.01$ & $0.63 \pm 0.02^{\mathrm{a}}$ & $0.59 \pm 0.01^{\mathrm{a}}$ & $0.61 \pm 0.02^{\mathrm{a}}$ \\
\hline
\end{tabular}

Abbreviations: ARB, angiotensin II receptor blocker; $\mathrm{Ccr}$, creatinine clearance; $\mathrm{Hb} \mathrm{A}_{1 \mathrm{c}}$, hemoglobin $\mathrm{A}_{1 \mathrm{c}}$ Data are expressed as the mean \pm s.e.

a $P<0.05$ vs. WKY/Izm.

b $P<0.05$ vs. vehicle-treated SHR/NDmcr-cp group.

${ }^{c} P<0.05$ vs. hydralazine group.
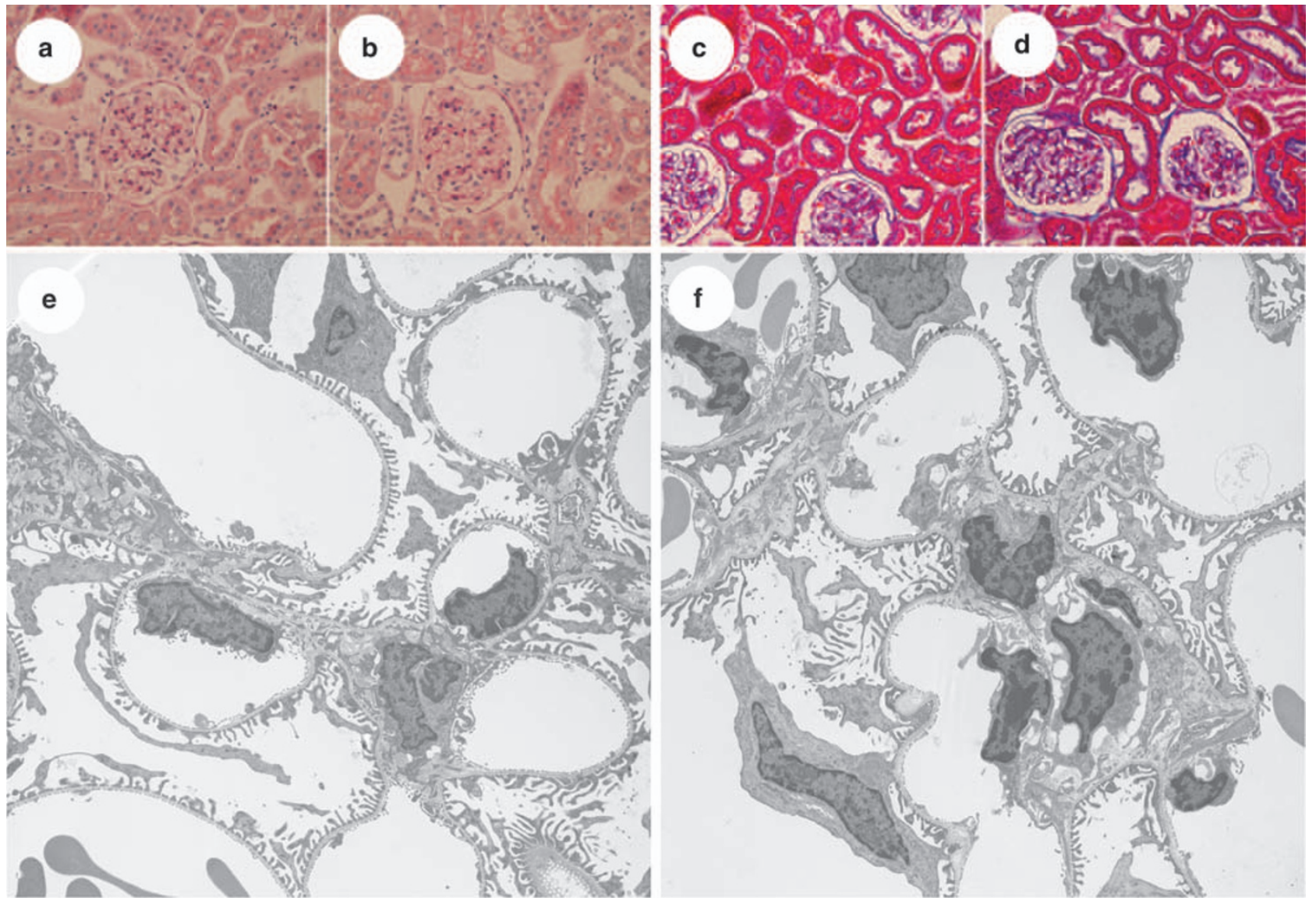

Figure 2 Histological analyses of the kidney in WKY/lzm rats and SHR/NDmcr-cp rats at 9 weeks of age/histological findings with periodic acid-schiff staining (a, b) and Azan staining (c, d). Transmission electron micrographs of the glomeruli (e, f). a, $\mathbf{c}, \mathbf{e}$ indicate WKY/lzm rats and $\mathbf{b}$, $\mathbf{d}$, $\mathbf{f}$ indicate SHR/NDmcr-cp rats.

significant glomerular damage, characterized by a thickening of the basement membrane, mesangial expansion and sclerosis, was present (Figure 3). The ARB-treated rats had significantly less glomerular damage (Figure 3d), but this renoprotective effect was not observed after treatment with hydralazine (Figure $3 \mathrm{c}$ ). The glomerular sclerosis score was higher in the vehicle-treated SHR/NDmcr-cp group than in
WKY/Izm rats (Table 3). For the SHR/NDmcr-cp rats, there was a significant improvement in the score in the ARB-treated group but not in the hydralazine-treated group compared with the vehicletreated group (Table 3 ).

The desmin-positive area around blood vessels (Figures $4 \mathrm{a}-\mathrm{d}$ ) and the number of PCNA-positive cells (Figures $4 \mathrm{e}-\mathrm{h}$ ) in the glomerulus 

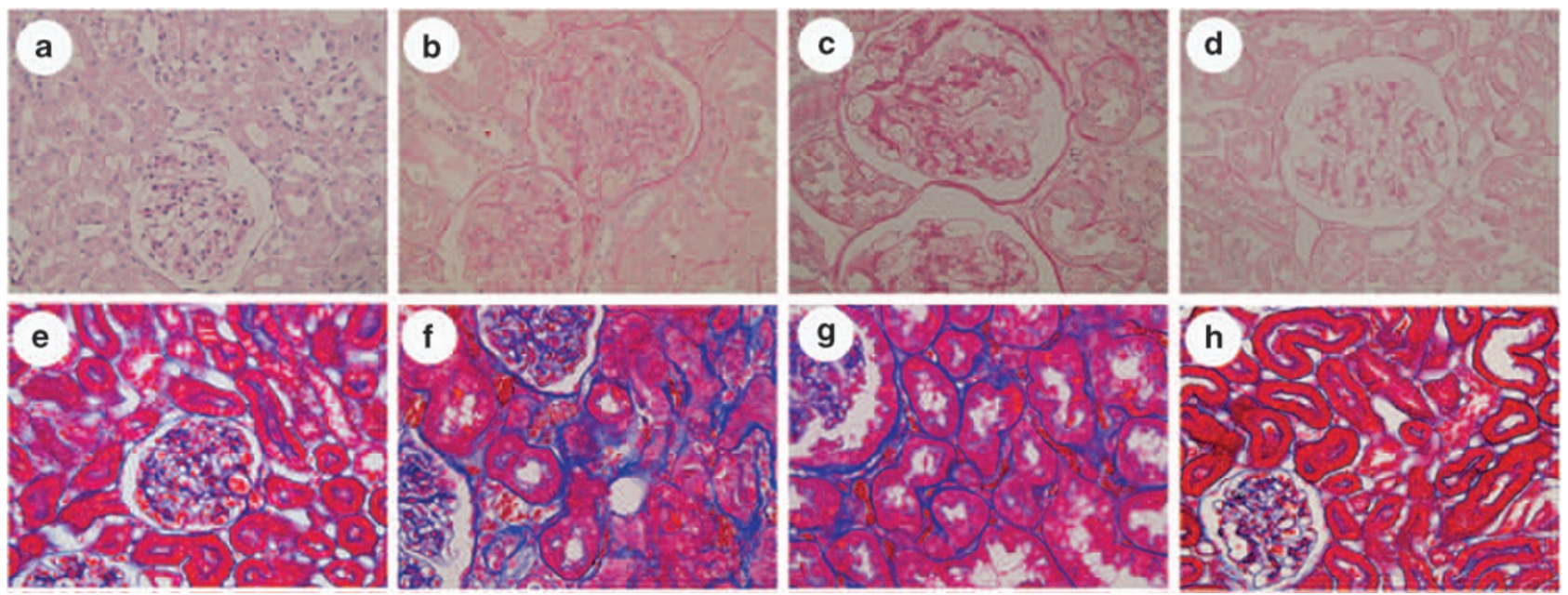

Figure 3 Histological analyses of renal injury after 12 weeks of treatment/histological findings of glomerular sclerosis with periodic acid-schiff staining (a-d) and tubulointerstitial fibrosis with Azan staining (e-h). $\mathbf{a}$, e indicate the WKY/Izm group; $\mathbf{b}, \mathbf{f}$ indicate the vehicle-treated SHR/NDmcr-cp group; $\mathbf{c}, \mathbf{g}$ indicate the hydralazine group and $\mathbf{d}, \mathbf{h}$ indicate the ARB group. Original magnifications: $\times 400$.

Table 3 Histological analyses of the glomerular and tubulointerstitial damages in WKY/Izm rats and SHR/NDmcr-cp rats after 12 weeks of treatments

\begin{tabular}{lccc}
\hline & & & SHR/NDmcr-cP \\
\cline { 3 - 4 } & WKY/Izm & Vehicle-treated & Hydralazine \\
\hline Glomerular damages & 4 & 4 & 4 \\
$\quad$ Glomerular sclerosis index & & & 4 \\
$\quad$ Desmin staining index & $0.30 \pm 0.10$ & $1.15 \pm 0.08^{\mathrm{a}}$ & $1.10 \pm 0.07$ \\
$\quad$ PCNA-positive cells per glomerulus & $1.20 \pm 0.09$ & $3.10 \pm 0.07^{\mathrm{a}}$ & $2.80 \pm 0.09$ \\
& $0.40 \pm 0.11$ & $2.70 \pm 0.10^{\mathrm{a}}$ & $2.35 \pm 0.11$ \\
Tubulointerstitial damages & & & $0.50 \pm 0.12^{\mathrm{b}, \mathrm{c}}$ \\
$\quad$ Tubulointerstitial fibrosis index & & & $1.75 \pm 0.10^{\mathrm{a}, \mathrm{b}, \mathrm{c}}$ \\
$\quad$ Type IV collagen staining index & $0.20 \pm 0.09$ & $1.40 \pm 0.11^{\mathrm{a}}$ & $1.10 \pm 0.07^{\mathrm{a}}$ \\
$\quad$ PCNA-positive cells per tubulointerstitial area & $1.25 \pm 0.10$ & $3.15 \pm 0.13^{\mathrm{a}}$ & $2.70 \pm 0.10^{\mathrm{a}}$ \\
\hline
\end{tabular}

Abbreviations: PAS, periodic acid-schiff; PCNA, proliferating cell nuclear antigen.

Glomerular sclerosis index and desmin staining index were estimated semiquantitatively by scoring as 0-4 or 1-4 degrees for PAS staining and desmin immunostaining, respectively.

Tubulointerstitial fibrosis index and Type IV collagen staining index were estimated semiquantitatively by scoring as 0-4 or 1-4 degrees for Azan staining and Type IV collagen

immunostaining, respectively. Data are expressed as the mean \pm s.e.

a $P<0.05$ vs. WKY/Izm.

${ }^{\mathrm{b}} P<0.05$ vs. vehicle-treated SHR/NDmcr-cp group.

c $P<0.05$ vs. hydralazine group.

were increased in the vehicle-treated SHR/NDmcr-cp group compared with those in WKY/Izm rats. These parameters were significantly decreased in the ARB-treated group, but they were unchanged between the hydralazine-treated and vehicle-treated groups. Semiquantitative analyses showed that both desmin-staining score and the number of PCNA-positive cells in the glomerulus decreased significantly in the ARB-treated group but not in the hydralazinetreated group (Table 2).

Tubulointerstitial fibrosis was more prominent in the vehicletreated SHR/NDmcr-cp group than in the WKY/Izm group and was improved in the ARB-treated group only (Figures 3e-h). The tubulointerstitial fibrosis score was significantly higher in the vehicle-treated SHR/NDmcr-cp group than in the control group. ARB treatment improved this score, whereas hydralazine treatment had no effect (Table 2). In addition, the total area of immunostaining for type IV collagen (Figures 4i-l) and the number of PCNA-positive cells (Figures $4 \mathrm{e}-\mathrm{h}$ ) in tubulointerstitial regions were greater in the vehicle-treated SHR/NDmcr-cp group than in WKY/Izm rats. There was a significant decrease in the amount of type IV collagen staining and PCNA-positive cells after treatment with ARB but not after treatment with hydralazine (Figures $4 \mathrm{e}-1$, Table 2).

\section{Ultrastructural analyses by transmission electron microscopy}

Electron microscopy showed a normal ultrastructure of the kidney in both SHR/NDmcr-cp rats and WKY/Izm rats at 9 weeks of age (Figures 2e and f). However, after 12 weeks of treatment, pathological changes in the glomerulus were observed at the ultrastructural level (Figure 5). Compared with age-matched WKY/Izm controls, the vehicle-treated SHR/NDmcr-cp group showed the following: (1) signs of podocyte injury including effacement and foot process fusion; 

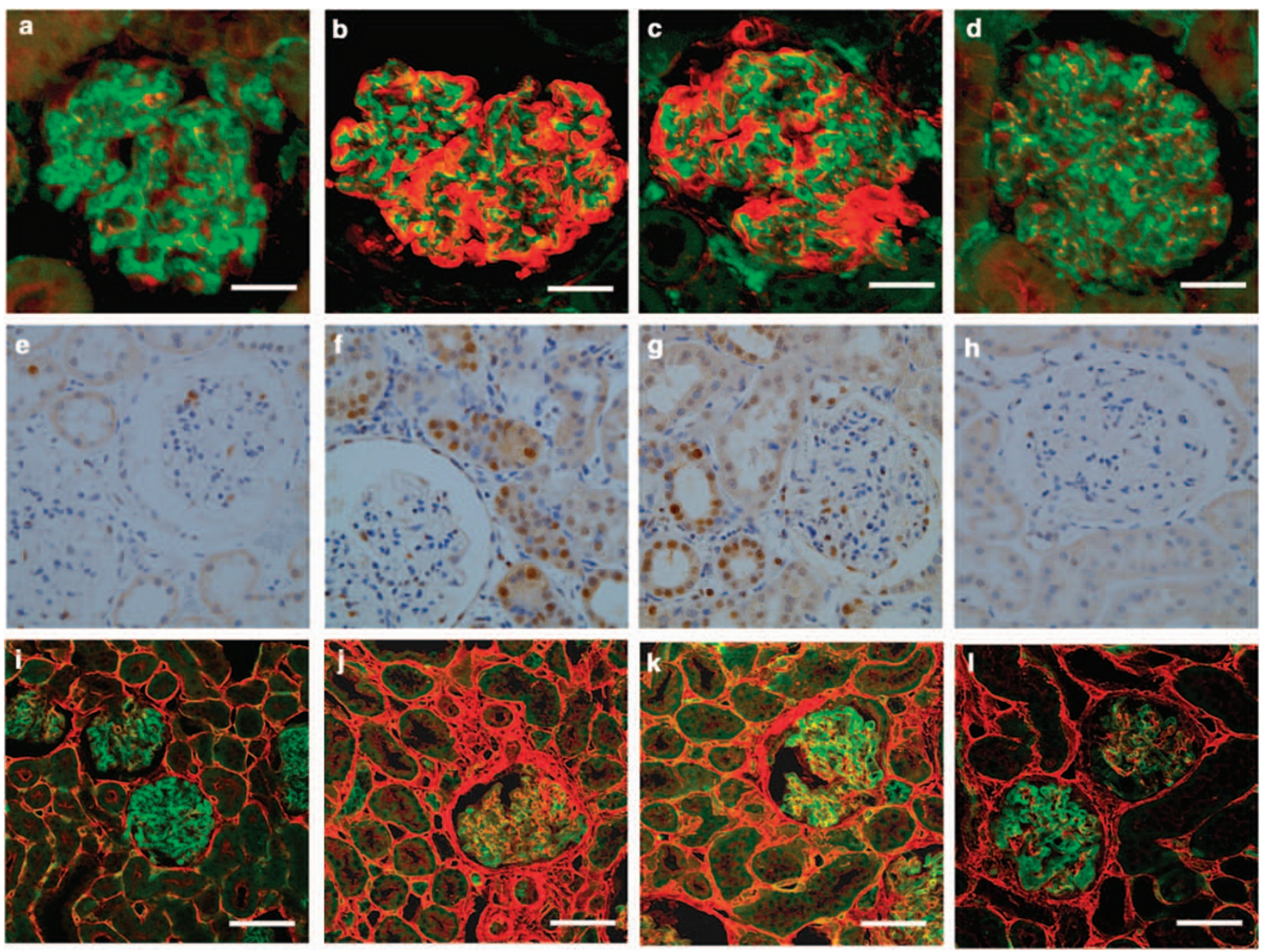

Figure 4 Immunohistochemical analyses of renal injury/double immunofluorescent staining of desmin (red) and lectin (green; a marker for blood vessels) in the WKY/Izm group (a), the vehicle-treated SHR/NDmcr-cp group (b), the hydralazine group (c) and the angiotensin II receptor blocker (ARB) group (d). Bar lengths: $25 \mu \mathrm{m}$. Immunostaining of proliferating cell nuclear antigen (PCNA) in the WKY/lzm group (e), the vehicle-treated SHR/NDmcr-cp group (f), the hydralazine group (g) and in the ARB group (h). Original magnifications: $\times 400$. Double immunofluorescent staining of type IV collagen (red) and lectin (green; a marker for blood vessels) in the WKY/Izm group (i), the vehicle-treated SHR/NDmcr-cp group (j), the hydralazine group (k) and in the ARB group (I). Bar lengths: $70 \mu \mathrm{m}$.

(2) narrowing and occlusion of glomerular vascular lumen and reduced endothelial fenestration; and (3) signs of mesangial injury including thickening and wrinkling of the glomerular basement membrane, proliferation of mesangial cells and increased interstitial substances (Figure 5b). These pathological changes were greatly improved in the ARB-treated group (Figure 5d). Hydralazine did not provide the same ultrastructural renoprotection as did ARB (Figure 5c).

\section{Expression of TGF- $\beta$ mRNA}

As TGF- $\beta$ is a known trigger of progressive fibrogenesis in chronic renal injury, we examined its expression in the kidney using RT-PCR. Expression of TGF- $\beta$ mRNA was significantly higher in the kidneys of vehicle-treated SHR/NDmcr-cp rats than in the kidneys of WKY/Izm rats. There was a significant decrease in the TGF- $\beta$ mRNA expression in the ARB-treated group that was not observed in the hydralazinetreated group (Figure 6).

\section{DISCUSSION}

In this study, we show that the SHR/NDmcr-cp rat strain, a model for MS, develops severe histological changes characteristic of renal glomerular injury and tubulointerstitial damage with age, resulting in increased UP excretion and decreased 24-h Ccr. These functional and morphological changes in the kidney can be improved by the administration of ARB.

As SHR/NDmcr-cp rats experience hypertension, obesity, type II diabetes mellitus and dyslipidemia, the observed renal damage is likely to be related to these disorders. The renoprotective effects of ARB treatment could be explained by its antihypertensive effect. As expected, there was a significant decrease in UP excretion in both the hydralazine-treated group and ARB recipients. It is noteworthy that proteinuria was significantly higher in SHR/NDmcr-cp rats than in WKY/Izm rats at 9 weeks of age. At that time, blood pressure was significantly different between the groups, but the kidneys did not show histological differences. Accordingly, it has been suggested that systemic hypertension, probably mediated by glomerular hypertension, is closely correlated with increased proteinuria in this model. However, our study shows that proteinuria was greatly improved in the ARB-treated group despite antihypertensive effects similar to those exerted by hydralazine. Therefore, the renoprotective effects of ARB treatment are independent of the blood pressure-lowering effect. 


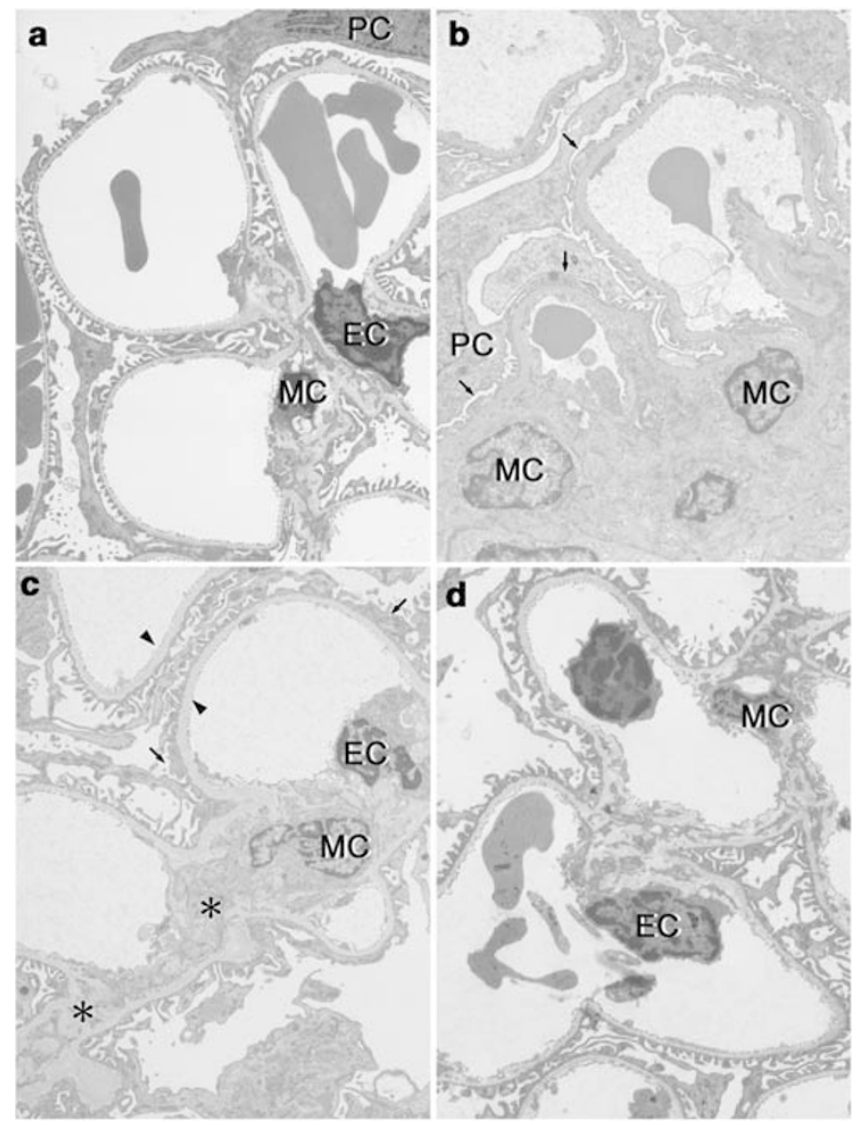

Figure 5 Transmission electron micrographs of the glomeruli/representative glomeruli in the age-matched control WKY/Izm group (a), the vehicle-treated SHR/NDmcr-cp group (b), the hydralazine-treated group (c) and in the angiotensin II receptor blocker (ARB)--treated group. Note that various signs of podocyte injury (arrow), basement membrane thickening and wrinkling (arrowhead) and mesangial injury $\left(^{*}\right)$ are prominent in both (b) and (c), but not in (d). EC, endothelial cell; MC, mesangial cell; PC, podocyte. Original magnifications: $\times 2000$.

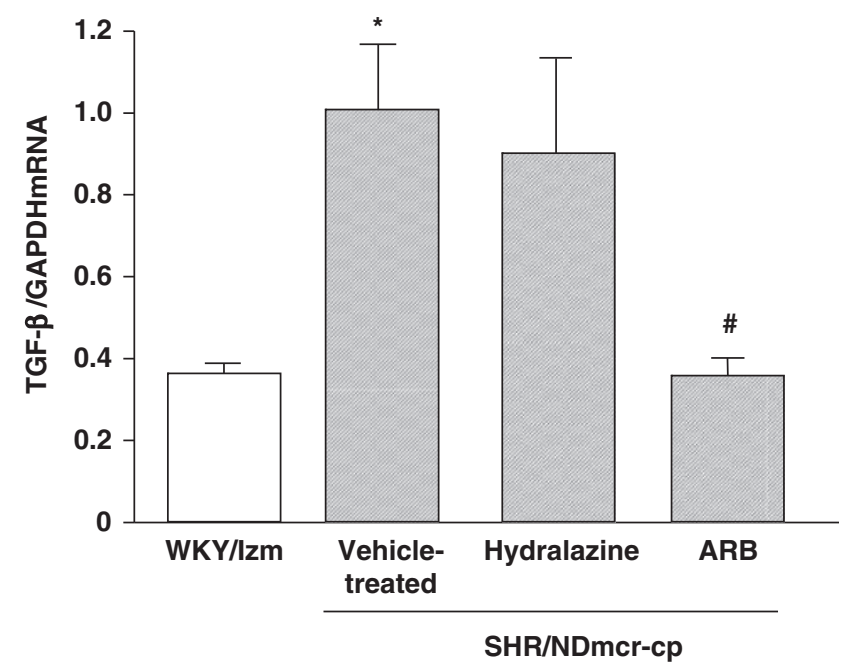

Figure 6 Expression of TGF- $\beta$ mRNA in the kidney/relative ratios of TGF- $\beta$ mRNA level to those of the vehicle-treated SHR/NDmcr-cp group were estimated by RT-PCR after 12 weeks of treatment. ${ }^{*} P<0.05$ vs. WKY/Izm group, ${ }^{\#} P<0.05$ vs. vehicle-treated SHR/NDmcr-cp group.
Ohtomo et al. ${ }^{20}$ showed that an improvement in hyperglycemia and dyslipidemia by thiazolidinediones mitigates renal damage in SHR/ NDmcr-cp rats. Namikoshi et al. ${ }^{22}$ showed that pioglitazone enhances the renoprotective effects of ARBs by improving lipid and glucose profiles in Zucker obese rats fed on a high-protein diet. However, there was no significant difference in body weight, glucose or lipid metabolism between vehicle-treated and ARB-treated SHR/NDmcr$\mathrm{cp}$ rats. These results suggest that the renoprotective effects of ARB treatment cannot be attributed to the effects of the drugs on metabolic factors.

In general, proteinuria in chronic kidney disease is associated with glomerulosclerosis, podocyte injury and tubulointerstitial fibrosis. Both the glomerular sclerosis index and the number of PCNA-positive cells in the glomeruli and tubulointerstitial areas were significantly increased in the vehicle-treated SHR/NDmcr-cp group. PCNA is one of the proteins involved in cell proliferation and DNA synthesis, and an increase in PCNA expression is a marker of glomerular sclerosis and tubulointerstitial injury. In addition, the expression of desmin as a marker of podocyte injury ${ }^{23-25}$ was significantly increased in the vehicle-treated SHR/NDmcr-cp group than in the WKY/Izm group. Previous studies have shown that podocyte damage is an early event leading to glomerulosclerosis and tubulointerstitial damage in Zucker obese rats with type II diabetes mellitus. ${ }^{26}$ We performed an electron microscopy to visualize podocyte injury. We showed podocyte fusion and effacement as well as mesangial injury, including thickening and wrinkling of the glomerular basement membrane, proliferation of mesangial cells and increased interstitial substances in the vehicletreated SHR/NDmcr-cp group. In addition to glomerular damage, we observed significant tubulointerstitial damage in the vehicle-treated SHR/NDmcr-cp group. Tubulointerstitial fibrosis index, type IV collagen staining on the peritubular basement membrane, number of PCNA-positive cells and expression of TGF- $\beta$ mRNA were all significantly increased in the vehicle-treated SHR/NDmcr-cp group.

By contrast, there was a significant decrease in the glomerular sclerosis index, the number of PCNA-positive cells and the expression of desmin in the ARB-treated group. These renoprotective effects were not observed in the hydralazine group. Tubulointerstitial damage was also significantly improved by ARB but not by hydralazine treatment. The ultrastructural changes showed by electron microscopy were also significantly improved by the ARB regimen but not by hydralazine.

Given that the renoprotective effects of ARB were independent of the systemic changes in blood pressure and glucose and lipid metabolism, more renal-specific effects of Ang II likely have an important role in kidney damage associated with MS. In support of this, Ang II has been shown to induce marked glomerular sclerosis ${ }^{27}$ with cell proliferation of the glomerular mesangium, ${ }^{28}$ vascular endothelium, ${ }^{29}$ tubular epithelium ${ }^{30}$ and the vascular smooth muscle. ${ }^{31}$ Ang II causes podocyte injury by increasing glomerular capillary pressure through a selective constriction of efferent arterioles. ${ }^{32,33}$ In addition, Ang II is thought to act directly on podocytes. Ideura et al. ${ }^{34}$ showed that Ang II infusion enhances morphological and phenotypical changes in podocytes in a murine model of HIV-associated nephropathy. In cultured podocytes, Ang II has been reported to affect the production of type IV collagen ${ }^{35}$ and the redistribution of the cytoskeleton, including the shedding of nephrin. ${ }^{36}$ Transgenic rats that express AT1R in podocytes develop albuminuria and structural podocyte damage progressing to focal segmental glomerulosclerosis. ${ }^{37}$ Ang II also stimulates tubulointerstitial fibrosis through collagen synthesis ${ }^{38}$ and TGF- $\beta$ expression ${ }^{39}$ through AT1 receptors. ${ }^{40,41}$ TGF- $\beta$ facilitates tubulointerstitial fibrosis by causing the accumulation of extracellular matrix and synthesis of type IV collagen in an Ang II-dependent manner. ${ }^{27,30,31}$ 
Plasma Ang II levels were similar in all experimental groups (data not shown), indicating that local, rather than circulating, RAS is likely to be involved. ${ }^{12,38}$ Previous reports of activated local RAS with an increased local production of Ang II and an expression of AT1 receptor in experimental rats modeling hypertension, diabetes mellitus and subtotal nephrectomy support this assertion. ${ }^{41-43}$ Taken together, these results suggest that ARBs exhibit renoprotective effects by blocking local RAS in the kidney.

Our study confirms a previous report by Izuhara et al., ${ }^{44}$ which first described the renoprotective effects of ARBs in SHR/NDmcr-cp rats. That group showed the renoprotective effects of ARB on the basis of histological, immunohistochemical and molecular biological analyses of glomerular and tubulointerstitial injuries. They also showed that renoprotective effects of ARBs are related to a decrease in oxidative stress and to an inhibition of advanced glycation end product formation by the Fenton reaction.

This study provides further evidence for the renoprotective effects of ARBs using various morphological and molecular biological markers for glomerular and tubulointerstitial injury: improved hematoxylin and eosin staining score, decrease in PCNA-positive cells as a marker of cell proliferation, electron microscopic findings showing an improvement in podocyte morphology and a decrease in the expression of collagen type IV and TGF- $\beta$ mRNA, which signify tubulointerstitial fibrosis. Expression of TGF- $\beta$ in the kidney has a crucial role in renal hypertrophy and mesangial matrix expansion in diabetic animals. ${ }^{45}$ Therefore, the effects of ARBs on TGF- $\beta$ expression are likely to be relevant to the drugs' renoprotective effects in SHR/ NDmcr-cp rats. Our present results, in accordance with previous reports, ${ }^{44}$ indicate that ARBs could be a useful therapeutic tool for MS associated with renal damage. Further studies are required to elucidate the mechanistic details responsible for the renoprotective effects of ARBs in the setting of MS.

\section{ACKNOWLEDGEMENTS}

We thank Daiichi-Sankyo (Tokyo, Japan) for providing olmesartan. We are very grateful to Ms Yoshiko Shimamoto for her excellent technical support and all staff of the Department of Anatomy and Developmental Biology of Tokyo Women's Medical University for their continuous support.

1 Chen J, Muntner P, Hamm LL, Jones DW, Batuman V, Fonseca V, Whelton PK, He J. The metabolic syndrome and chronic kidney disease in US adults. Ann Intern Med 2004; 140: 167-174.

2 Kawamoto R, Kohara K, Tabara Y, Miki T, Ohtsuka N, Kusunoki T, Yorimitsu N. An association between body mass index and estimated glomerular filtration rate. Hypertens Res 2008; 31: 1559-1564.

3 Serra A, Romero R, Lopez D, Navarro M, Esteve A, Perez N, Alastrue A, Ariza A. Renal injury in the extremely obese patients with normal renal function. Kidney Int 2008; 73: 947-955.

4 Praga M, Morales E. Obesity, proteinuria and progression of renal failure. Curr Opin Nephrol Hypertens 2006; 15: 481-486.

5 Verani RR. Obesity-associated focal segmental glomerulosclerosis: pathological features of the lesion and relationship with cardiomegaly and hyperlipidemia. Am J Kidney Dis 1992; 20: 629-634.

6 Navarro-Diaz M, Serra A, Romero R, Bonet J, Bayes B, Homs M, Perez N, Bonal J. Effect of drastic weight loss after bariatric surgery on renal parameters in extremely obese patients: long-term follow-up. J Am Soc Nephrol 2006; 17: S213-S217.

7 Chagnac A, Weinstein T, Korzets A, Ramadan E, Hirsch J, Gafter U. Glomerular hemodynamics in severe obesity. Am J Physiol Renal Physiol 2000; 278: F817-F822.

8 Kasiske BL, Napier J. Glomerular sclerosis in patients with massive obesity. Am J Nephrol 1985; 5: 45-50.

9 Kambham N, Markowitz GS, Valeri AM, Lin J, D'Agati VD. Obesity-related glomerulopathy: an emerging epidemic. Kidney Int 2001; 59: 1498-1509.

10 de Jong PE, Verhave JC, Pinto-Sietsma SJ, Hillege HL. Obesity and target organ damage: the kidney. Int J Obes Relat Metab Disord 2002; 26(Suppl 4): S21-S24.

11 Abbate M, Zoja C, Remuzzi G. How does proteinuria cause progressive renal damage? J Am Soc Nephrol 2006; 17: 2974-2984.
12 Ruster C, Wolf G. Renin-angiotensin-aldosterone system and progression of renal disease. J Am Soc Nephrol 2006; 17: 2985-2991.

13 Brenner BM, Cooper ME, de Zeeuw D, Keane WF, Mitch WE, Parving HH, Remuzzi G, Snapinn SM, Zhang Z, Shahinfar S, RENAAL Study Investigators. Effects of losartan on renal and cardiovascular outcomes in patients with type 2 diabetes and nephropathy. N Engl J Med 2001; 345: 861-869.

14 Lewis EJ, Hunsicker LG, Clarke WR, Berl T, Pohl MA, Lewis JB, Ritz E, Atkins RC, Rohde R, Raz I, Collaborative Study Group. Renoprotective effect of the angiotensinreceptor antagonist irbesartan in patients with nephropathy due to type 2 diabetes. N Engl J Med 2001; 345: 851-860.

15 Landsberg L. Pathophysiology of obesity-related hypertension: role of insulin and the sympathetic nervous system. J Cardiovasc Pharmacol 1994; 23 (Suppl 1): S1-S8.

16 Engeli S, Negrel R, Sharma AM. Physiology and pathophysiology of the adipose tissue renin-angiotensin system. Hypertension 2000; 35: 1270-1277.

17 Goodfriend TL, Kelley DE, Goodpaster BH, Winters SJ. Visceral obesity and insulin resistance are associated with plasma aldosterone levels in women. Obes Res 1999; 7: 355-362.

18 Takaya K, Ogawa Y, Hiraoka J, Hosoda K, Yamori Y, Nakao K, Koletsky RJ. Nonsense mutation of leptin receptor in the obese spontaneously hypertensive Koletsky rat. Nat Genet 1996; 14: 130-131.

19 Ernsberger P, Johnson JL, Rosenthal T, Mirelman D, Koletsky RJ. Therapeutic actions of allylmercaptocaptopril and captopril in a rat model of metabolic syndrome. $A m \mathrm{~J}$ Hypertens 2007; 20: 866-874.

20 Ohtomo S, Izuhara Y, Takizawa S, Yamada N, Kakuta T, van Ypersele de Strihou C, Miyata T. Thiazolidinediones provide better renoprotection than insulin in an obese, hypertensive type II diabetic rat model. Kidney Int 2007; 72: 1512-1519.

21 Toblli JE, Ferder L, Angerosa M, Inserra F. Effects of amlodipine on tubulointerstitial lesions in normotensive hyperoxaluric rats. Hypertension 1999; 34: 854-858.

22 Namikoshi T, Tomita N, Satoh M, Haruna Y, Kobayashi S, Komai N, Sasaki T, Kashihara N. Pioglitazone enhances the antihypertensive and renoprotective effects of candesar$\tan$ in Zucker obese rats fed a high-protein diet. Hypertens Res 2008; 31: 745-755.

23 Floege J, Alpers CE, Sage EH, Pritzl P, Gordon K, Johnson RJ, Couser WG. Markers of complement-dependent and complement-independent glomerular visceral epithelial cell injury in vivo. Expression of antiadhesive proteins and cytoskeletal changes. Lab Invest 1992; 67: 486-497.

24 Muchaneta-Kubara EC, el Nahas AM. Myofibroblast phenotypes expression in experimental renal scarring. Nephrol Dial Transplant 1997; 12: 904-915.

25 Janssen U, Riley SG, Vassiliadou A, Floege J, Phillips AO. Hypertension superimposed on type II diabetes in Goto Kakizaki rats induces progressive nephropathy. Kidney Int 2003; 63: 2162-2170.

26 Coimbra TM, Janssen U, Grone HJ, Ostendorf T, Kunter U, Schmidt H, Brabant G, Floege J. Early events leading to renal injury in obese Zucker (fatty) rats with type II diabetes. Kidney Int 2000; 57: 167-182.

27 Erman A, Veksler S, Gafter U, Boner G, Wittenberg C, van Dijk DJ. Renin-angiotensin system blockade prevents the increase in plasma transforming growth factor beta 1 , and reduces proteinuria and kidney hypertrophy in the streptozotocin-diabetic rat. $J$ Renin Angiotensin Aldosterone Syst 2004; 5: 146-151.

28 Johnson RJ, Alpers CE, Yoshimura A, Lombardi D, Pritzl P, Floege J, Schwartz SM. Renal injury from angiotensin II-mediated hypertension. Hypertension 1992; 19: 464-474.

29 Nangaku M. Mechanisms of tubulointerstitial injury in the kidney: final common pathways to end-stage renal failure. Intern Med 2004; 43: 9-17.

30 Gilbert RE, Cox A, Wu LL, Allen TJ, Hulthen UL, Jerums G, Cooper ME. Expression of transforming growth factor-betal and type IV collagen in the renal tubulointerstitium in experimental diabetes: effects of ACE inhibition. Diabetes 1998; 47: 414-422.

31 Russo LM, del Re E, Brown D, Lin HY. Evidence for a role of transforming growth factor (TGF)-beta1 in the induction of postglomerular albuminuria in diabetic nephropathy: amelioration by soluble TGF-beta type II receptor. Diabetes 2007; 56: 380-388.

32 Denton KM, Fennessy PA, Alcorn D, Anderson WP. Morphometric analysis of the actions of angiotensin II on renal arterioles and glomeruli. Am J Physiol 1992; 262: F367-F372.

33 Yuan BH, Robinette JB, Conger JD. Effect of angiotensin II and norepinephrine on isolated rat afferent and efferent arterioles. Am J Physiol 1990; 258: F741-F750.

34 Ideura H, Hiromura K, Hiramatsu N, Shigehara T, Takeuchi S, Tomioka M, Sakairi T, Yamashita S, Maeshima A, Kaneko Y, Kuroiwa T, Kopp JB, Nojima Y. Angiotensin II provokes podocyte injury in murine model of HIV-associated nephropathy. Am J Physiol Renal Physiol 2007; 293: F1214-F1221.

35 Chen S, Lee JS, Iglesias-de la Cruz MC, Wang A, Izquierdo-Lahuerta A, Gandhi NK, Danesh FR, Wolf G, Ziyadeh FN. Angiotensin II stimulates alpha3(IV) collagen production in mouse podocytes via TGF-beta and VEGF signalling: implications for diabetic glomerulopathy. Nephrol Dial Transplant 2005; 20: 1320-1328.

36 Macconi D, Abbate M, Morigi M, Angioletti S, Mister M, Buelli S, Bonomelli M, Mundel $P$, Endlich K, Remuzzi A, Remuzzi G. Permselective dysfunction of podocyte-podocyte contact upon angiotensin II unravels the molecular target for renoprotective intervention. Am J Pathol 2006; 168: 1073-1085.

37 Hoffmann S, Podlich D, Hahnel B, Kriz W, Gretz N. Angiotensin II type 1 receptor overexpression in podocytes induces glomerulosclerosis in transgenic rats. J Am Soc Nephrol 2004; 15: 1475-1487.

38 Nishiyama A, Seth DM, Navar LG. Renal interstitial fluid concentrations of angiotensins I and II in anesthetized rats. Hypertension 2002; 39: 129-134.

39 Wu LL, Cox A, Roe CJ, Dziadek M, Cooper ME, Gilbert RE. Secreted protein acidic and rich in cysteine expression after subtotal nephrectomy and blockade of the renin-angiotensin system. J Am Soc Nephrol 1997; 8: 1373-1382. 
40 Zhuo JL, Li XC. Novel roles of intracrine angiotensin II and signalling mechanisms in kidney cells. J Renin Angiotensin Aldosterone Syst 2007; 8: 23-33.

41 Kobori H, Ozawa Y, Suzaki Y, Nishiyama A. Enhanced intrarenal angiotensinogen contributes to early renal injury in spontaneously hypertensive rats. J Am Soc Nephrol 2005; 16: 2073-2080.

42 Nagai Y, Yao L, Kobori H, Miyata K, Ozawa Y, Miyatake A, Yukimura T, Shokoji T, Kimura $\mathrm{S}$, Kiyomoto H, Kohno M, Abe Y, Nishiyama A. Temporary angiotensin II blockade at the prediabetic stage attenuates the development of renal injury in type 2 diabetic rats. J Am Soc Nephrol 2005; 16: 703-711.
43 Singh R, Alavi N, Singh AK, Leehey DJ. Role of angiotensin II in glucose-induced inhibition of mesangial matrix degradation. Diabetes 1999; 48: 2066-2073.

44 Izuhara Y, Nangaku M, Inagi R, Tominaga N, Aizawa T, Kurokawa K, van Ypersele de Strihou C, Miyata T. Renoprotective properties of angiotensin receptor blockers beyond blood pressure lowering. J Am Soc Nephrol 2005; 16: 3631-3641.

45 Langham RG, Kelly DJ, Gow RM, Zhang Y, Cordonnier DJ, Pinel N, Zaoui P, Gilbert RE. Transforming growth factor-beta in human diabetic nephropathy: effects of ACE inhibition. Diabetes Care 2006; 29: 2670-2675. 